\title{
Bayesian Knowledge Tracing for Navigation through Marzano's Taxonomy
} \author{
Valentín ${ }^{4}$ \\ ${ }^{1}$ Universidad Internacional de La Rioja en México, Mexico City (Mexico) \\ ${ }^{2}$ Universidad Nacional Autónoma de México, Mexico City (Mexico) \\ ${ }^{3}$ Instituto Tecnológico Autónomo de México, Mexico City (Mexico) \\ ${ }^{4}$ Universidad Internacional de La Rioja, Logroño (Spain)
}

Francisco Cervantes-Pérez ${ }^{1 *}$, Joaquin Navarro-Perales², Ana L. Franzoni-Velázquez ${ }^{3}$, Luis de la Fuente-

Received 27 June 2020 | Accepted 24 April 2021 | Published 14 May 2021

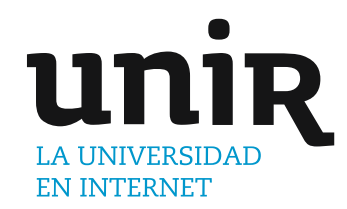

\section{ABSTRACT}

In this paper we propose a theoretical model of an ITS (Intelligent Tutoring Systems) capable of improving and updating computer-aided navigation based on Bloom's taxonomy. For this we use the Bayesian Knowledge Tracing algorithm, performing an adaptive control of the navigation among different levels of cognition in online courses. These levels are defined by a taxonomy of educational objectives with a hierarchical order in terms of the control that some processes have over others, called Marzano's Taxonomy, that takes into account the metacognitive system, responsible for the creation of goals as well as strategies to fulfill them. The main improvements of this proposal are: 1) An adaptive transition between individual assessment questions determined by levels of cognition. 2) A student model based on the initial response of a group of learners which is then adjusted to the ability of each learner. 3) The promotion of metacognitive skills such as goal setting and self-monitoring through the estimation of attempts required to pass the levels. One level of Marzano's taxonomy was left in the hands of the human teacher, clarifying that a differentiation must be made between the tasks in which an ITS can be an important aid and in which it would be more difficult.

\author{
KEYWORDS \\ Bayesian Knowledge \\ Tracing, Bloom's \\ Taxonomy, Computer- \\ Assisted Instruction, \\ Intelligent Tutoring \\ System, Marzano's \\ Taxonomy.
}

DOI: $10.9781 /$ ijimai.2021.05.006

\section{INTRODUCTION}

$\mathrm{T}$ HE use of computers as helping devices in education started in the early 1960s [1], this was called Computer Assisted Instruction (CAI), which interacted directly with the student, rather than assisting a human professor. A text with questions was shown to the student, who had to provide a brief answer and a set of instructions, and then let the system continue with the next questions. The answers provided by the student were evaluated by the system according to specific patterns. CAIs were frame-oriented systems where, sometimes, students' learning was stimulated while they were engaged in some activity, such as a simulation or a game [2].

During the 70s some Artificial Intelligence (AI) techniques were added to CAI design and were redefined as knowledge-based or Intelligent Computer-Aided Instruction (ICAI) [2]. The teaching strategies were provided by human teachers and written as a set of rules that ICAIs had to apply, to lead students towards an efficient learning process of the subject. In addition, the development of ICAIs allowed the introduction of didactic material to analyze the student's performance after the application of individual tutoring strategies.

Hartley and Sleeman, based on their definition of "intelligent teaching", described that "a necessary ingredient of an intelligent

* Corresponding author.

E-mail address: francisco.cervantesperez@unir.net teaching system is a decision-making algorithm which has specific information about the teaching domain and objectives" [3]. In addition, they identified two types of components necessary to implement ICAI's decision-making procedures: first, a knowledge representation, for the teaching task and the student model; and second, a control strategy, based on a set of teaching operations and a set of mean-ends guidance rules.

ICAIs were rebranded as ITS (Intelligent Tutoring Systems) and defined as dynamic and adaptive systems for personalized instruction based on students' characteristics and behavior. Their design is the outcome of integrating knowledge from various fields such as: AI, cognitive psychology and educational research. The architecture of an ITS is composed by four modules [4]:

- Domain model: It contains knowledge about the subjects that must be learned. It is also called knowledge model.

- Student model. The structure that stores the student's knowledge status, what the student knows or does not know about the domain.

- Instructional model. It defines the teaching and tutorial strategies. It is also called the teacher model or pedagogical module.

- Interface. It is the media that allows the interaction between the user and the computational system.

Fig. 1 shows the architecture based on these four modules and the way in which the flow of information between them and the user is performed. 


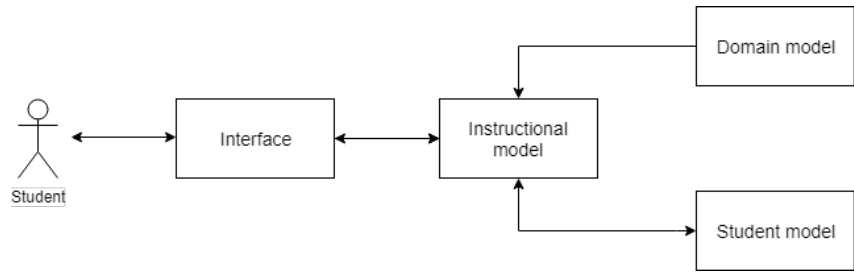

Fig. 1. Architecture of an Intelligent Tutoring System.

From the beginning of the development of ITS there is a very important criticism against them, which consists in affirming that they are not well grounded in a model of learning, and that they seem more motivated by available technology than by educational needs [4]. That is why the authors of this work propose to start from a student advancement system through a taxonomy of educational objectives used in a previous CAI system [5], updating its cognitive foundations and at the same time adding adaptability through a Bayesian model.

The purpose of this work is to propose a theoretical model of an ITS capable of improving and updating computer-aided navigation based on cognitive levels. Our main contribution is the articulation of Marzano's taxonomy of educational objectives, which takes into account the metacognitive system, with the Bayesian Knowledge Tracing algorithm to probabilistically model learners' knowledge.

\section{Previous Work}

We classified Intelligent Tutoring Systems into three big groups:

1. Knowledge tracing systems: The systems in the first category model the mastery level of learners and make predictions about it. Some examples are Bayesian Networks to implement a control shared between the students and the machine to track the process of studying linear equations [6], the use of Artificial Neural Networks in children games to determine the right amount of difficulty for each user [7] and Formal Concept Analysis to determine the type of feedback corresponding to each student when solving a given task [8].

2. Conversational agents: Systems in this category use natural language processing to interact with students simulating a human conversation, this is possible because students type text strings either in chat like interfaces or Learning Management Systems sections, and then they are computationally processed. Some examples of the techniques used in these systems and their objectives are semantic web technologies to let students inspect, discuss, and alter their learner models [9], ontologies to model cultural awareness of users through DBpedia database [10], and semantic processing based on conceptual representations to autonomously respond to students' introductions, posted weekly announcements, and answer frequently asked questions [11].

3. Affective tutoring systems (ATS): They are ITS that track the emotional state of student [12]. It is worth mentioning that most of the time a generalized emotional response is estimated, not towards specific problems. ATS are divided into two categories, sensor-based, and sensor-free:

Sensor based ATS: They use devices such as physiological sensors, pressure sensors, cameras, and eye-trackers. Some examples of these prototypes use photoplethysmographic signals to track reading difficulty [13], a mouse with pressure sensors to measure students' stress [14], facial recognition and the measurement of skin conductance to determine the affective response to concrete problems [15], and eye-tracking to hypermedia environment adaptation [16].
Sensor-free ATS: They aim to find a correlation between students' emotions and characteristics like interaction logs like number of hints seen, number of hints available, number of skipped tasks, time spent for tasks and time between actions [17] and filled surveys or self-assessment reports, where students report their own feelings, emotions, or mood in a particular learning situation [18]. There are also scopes belonging to this category or to the conversational agents' category and they aim to monitor students' emotions through their interaction with chatbots [19].

Table I shows nine intelligent tutoring systems that are important for the proposal of this work.

As we can see, Bayesian techniques are used to classify learners according to their characteristics and to model their knowledge and performance in an adaptive way. We can also observe that most of the jobs in Table I are based on the level of knowledge of the learners. Our proposal consists of a knowledge tracking system based on a Bayesian model that guides students through specific cognitive levels, to select these levels, we start from the navigation of a CAI system called SAGE.

\section{SAGE}

SAGE (Sistema de Apoyo Generalizado para la Enseñanza Individualizada) is a CAI system developed at Tecnológico Autónomo de México (ITAM) [5]. The system has the following characteristics:

\section{A. Individual Teaching}

SAGE allows the learner to select a sequence of topics while meeting the prerequisites for each lesson. This individual teaching approach allows students to take into account variations in their scores and to compare it with the group average, noting their position inside the group.

\section{B. Content Map}

SAGE is based on a content map that organizes subjects from the general to the particular and dependencies are established between the course subjects. Therefore, if the students need to check subjects where they do not need previous knowledge, they will be able to do that, but if they do not have the pre-requirements, the system will not allow them to see the lessons.

\section{Bloom's Taxonomy}

Students can progress through lessons solving tests according to the levels of Bloom's taxonomy, this taxonomy operationalizes thinking processes inside a hierarchy which helps to select, describe and evaluate the behaviors that are going to be taught. This is derived from a learning model that considers three domains: cognitive, affective, and psychomotor [29]. The authors proposed six levels for the cognitive level:

- Knowledge: Involves all those behaviors that consist of memorization.

- Comprehension: Understand the message inside the communication process

- Application: It is the transference of acquired knowledge to similar or almost new situations, this means, to make generalizations.

- Analysis: Split knowledge in their constitutive elements so the relative hierarchy of ideas appears clearly.

- Synthesis: It means the reunion of the elements and parts to form a whole.

- Evaluation: Consists in judging if a determined set of knowledge satisfies or not a specific criterion.

SAGE covers the first four levels of Bloom's taxonomy (knowledge, comprehension, application, and analysis) according to specific types 
TABLE I. EXAmpLES OF INTELLIGENT Tutoring Systems

\begin{tabular}{|c|c|c|c|c|}
\hline Authors & Educational field & IA techniques & Purposes of IA techniques & Learner's characteristics \\
\hline $\begin{array}{l}\text { Muñoz, Ortiz, Gonzalez, } \\
\text { Lopez, and Blobel [20] }\end{array}$ & $\begin{array}{l}\text { Childhood disease } \\
\text { management }\end{array}$ & $\begin{array}{l}\text { - Bayesian technique (Bayesian } \\
\text { network) }\end{array}$ & $\begin{array}{l}\text { - Define and update student's } \\
\text { knowledge level }\end{array}$ & $\begin{array}{l}\text { - Learner's knowledge } \\
\text { - Learner's performance }\end{array}$ \\
\hline $\begin{array}{l}\text { Weragama and Reye } \\
\text { [23] }\end{array}$ & $\begin{array}{l}\text { Computer } \\
\text { programming }\end{array}$ & $\begin{array}{l}\text { - Bayesian-based technique } \\
\text { (Bayesian network) }\end{array}$ & $\begin{array}{l}\text { - Determining and updating the } \\
\text { student model }\end{array}$ & $\begin{array}{l}\text { - Learner's responses to } \\
\text { learning activities }\end{array}$ \\
\hline $\begin{array}{l}\text { El Ghouch, El Mokhtar, } \\
\text { and Seghroucheni [26] }\end{array}$ & $\begin{array}{l}\text { Designed for variant } \\
\text { courses }\end{array}$ & $\begin{array}{l}\text { - Bayesian technique (Bayesian } \\
\text { network classifying) }\end{array}$ & $\begin{array}{l}\text { - Classifying the learners based } \\
\text { on learning styles }\end{array}$ & - Learning style \\
\hline $\begin{array}{l}\text { Grivokostopoulou, } \\
\text { Perikos, and } \\
\text { Hatzilygeroudis [27] }\end{array}$ & AI curriculum & $\begin{array}{l}\text { - Condition action rule-based } \\
\text { reasoning (Rule-based expert } \\
\text { system) } \\
\text { - Data mining technique } \\
\text { (decision tree) }\end{array}$ & $\begin{array}{l}\text { - Presenting adaptive exercises } \\
\text { - Learners evaluation } \\
\text { (prediction of the student } \\
\text { performances) }\end{array}$ & $\begin{array}{l}\text { - Learner's knowledge level } \\
\text { - Learner's performance }\end{array}$ \\
\hline $\begin{array}{l}\text { Mostafavi and Barnes } \\
{[28]}\end{array}$ & $\begin{array}{l}\text { Philosophy \& } \\
\text { Computer science } \\
\text { (solving logic proof } \\
\text { problems) }\end{array}$ & $\begin{array}{l}\text { - Bayesian-based technique } \\
\text { (Bayesian knowledge tracing) } \\
\text { - Data mining technique } \\
\text { (Cluster-based classification) }\end{array}$ & $\begin{array}{l}\text { - Evaluation and prediction of } \\
\text { the learner's performance } \\
\text { - Classification of the learners } \\
\text { based on their performances }\end{array}$ & $\begin{array}{l}\text { - Student performance } \\
\text { - Learner's knowledge }\end{array}$ \\
\hline
\end{tabular}

TABLE II. Correspondence Between Strategies and Cognitive Levels

\begin{tabular}{cccccc}
\hline Type of question & Knowledge & Comprehension & Application & Analysis & Synthesis \\
\hline Brief answer & $\checkmark$ & $\checkmark$ & & & \\
Completing & $\checkmark$ & $\checkmark$ & $\checkmark$ & $\checkmark$ & \\
Multiple option & $\checkmark$ & $\checkmark$ & $\checkmark$ & $\checkmark$ \\
Matching & $\checkmark$ & $\checkmark$ & & $\checkmark$ \\
Alternative answer & & & $\checkmark$ & $\checkmark$ \\
Arranging & $\checkmark$ & & $\checkmark$ & \\
$\quad$ Essay & & & $\checkmark$ & \\
\hline
\end{tabular}

of questions, Table II shows the correspondence between evaluation strategies and cognitive levels.

Fig. 2 shows the steps that a learner must carry out in SAGE to select and pass a lesson, and the steps carried out within each of the first four cognitive levels of Bloom's taxonomy (knowledge, comprehension, application, and analysis).

\section{PROPOSAL}

The characteristics and operating principles of the proposed ITS are described below.

\section{A. Adaptive Learning}

The system will allow the navigation path between lessons to automatically adapt to the progress of the learner's skills. For this, the student model starts from the performance of the group to later adapt to individual needs through the Bayesian model.

\section{B. Bayesian Knowledge Tracing}

Transitions between lessons are defined according to the Bayesian Knowledge Tracing algorithm, a tool developed by Anderson and Corbett [30] that modelled the acquisition of knowledge and skills as a Hidden Markov Model, this means, a Markov process with unknown parameters known as hidden states that must be determined from some observable outputs. The unknown parameters are the knowledge and skills that students should possess when their lessons are finished, and the observable outputs are the answers to the evaluation questions, where two options exist: "right" and "wrong".

A personalized sequence of questions is presented to the learner based on probability estimates until the student has mastered each skill. The transition probability represents the odds of a progression between knowledge units, while the emission probability represents the odds of an accurate evaluation. Both probabilities are calculated through a computational procedure that is a variation on one described by Atkinson [31] that employs two learning parameters and 


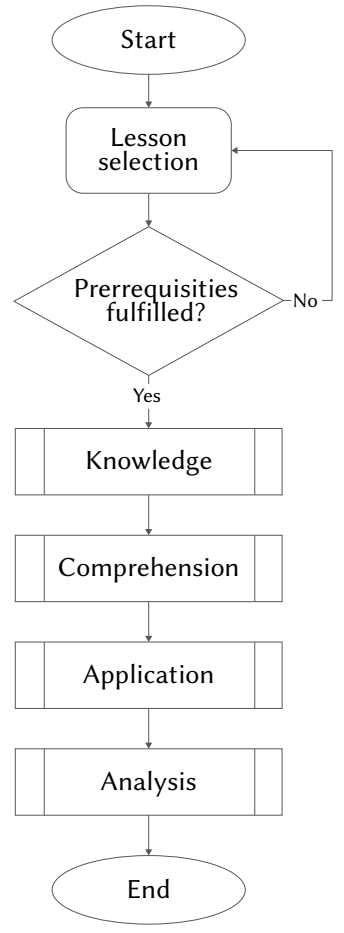

a)

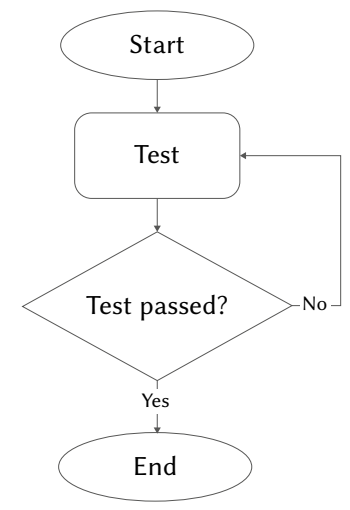

b)
Fig. 2. Navigation in SAGE through the levels of Bloom's taxonomy. a) Workflow of a lesson. b) Subprocess that represents the steps within knowledge, comprehension, application, and analysis.

two performance parameters: Initial Learning or $\mathrm{p}\left(\mathrm{L}_{0}\right)$ is a learning parameter that indicates the probability that a skill is in the learned state prior to the first opportunity to apply it, Transition or $\mathrm{p}(\mathrm{T})$ was described before as the transition probability and it is the second learning parameter. On the other hand, the emission probability is decomposed into two performance parameters: Guess or $p(G)$ is the probability that a student will guess correctly if a skill is in the unlearned state and Slip or $\mathrm{p}(\mathrm{S})$ is the probability that a student will make a mistake if a skill is in the learned state. Equations (1), (2), and (3) show the relations between parameters when Initial Learning is updated to $\mathrm{p}\left(\mathrm{L}_{\mathrm{n}}\right)$ [32] where $\mathrm{n}$ is the discrete time measure that increases each time an exercise is answered, what is called Action $_{\mathrm{n}}$.

$$
\begin{aligned}
& P\left(L_{n-1} \mid \text { Correct }_{n}\right)=\frac{P\left(L_{n-1}\right) *(1-P(S))}{P\left(L_{n-1}\right) *(1-P(S))+\left(1-P\left(L_{n-1}\right)\right) *(P(G))} \\
& P\left(L_{n-1} \mid \text { Incorrect }_{n}\right)=\frac{P\left(L_{n-1}\right) * P(S)}{P\left(L_{n-1}\right) * P(S)+\left(1-P\left(L_{n-1}\right)\right) *(1-P(G))} \\
& P\left(L_{n} \mid \text { Action }_{n}\right)=P\left(L_{n-1} \mid \text { Action }_{n}\right)+\left(\left(1-P\left(L_{n-1} \mid \text { Action }_{n}\right)\right) * P(T)\right)
\end{aligned}
$$

Every Action $_{n}$ has two possible results: correct answer (Correct ${ }_{n}$ ) or incorrect answer (Incorrect $\mathrm{n}_{\mathrm{n}}$ ). In this way, the parameters $\mathrm{p}\left(\mathrm{L}_{0}\right)$, $p(T), p(G)$ and $p(S)$ can be calculated from the group's answers, and as each student solves the questions, their $\mathrm{p}\left(\mathrm{L}_{\mathrm{n}}\right)$ will progressively be adjusted depending on whether their individual answers are correct or incorrect.

\section{Marzano's Taxonomy}

The questions that allow making transitions between lessons are planned according to Marzano's taxonomy, a taxonomy of educational objectives that proposes a hierarchical order in terms of the control that some processes have over others. The model presents three mental systems: self- system, metacognitive system, and the cognitive system. When the execution of a new task is required, the self-system is responsible for assessing the importance of the task, the probability of success, the present motivation to accomplish it, and the emotional response to the task. Depending on these factors the task is accepted or rejected. When the task is selected, the metacognitive system is responsible for the creation of goals to be achieved, as well as strategies to fulfill these goals. Later, the cognitive system deals with information processing and the analytical operations through four levels of cognition: retrieval, comprehension, analysis, and knowledge utilization [33]. Table III shows correspondence between systems, levels and tasks in Marzano's taxonomy.

The automation of the fourth level of Marzano's taxonomy, which corresponds to knowledge utilization, would require advanced evaluation of texts, therefore the experimental work would be difficult to take into account. The complexity of this level is high for the machine while for the human tutor it is almost intuitive. According to this, the level of utilization of knowledge will be for now in the hands of the human tutors. On the contrary, the Bayesian Knowledge Tracing algorithm will guide the transitions between the retrieval, comprehension, and analysis levels in which it is more feasible to use questionnaires with correct and incorrect answers.

TABLE III. Systems, Levels, AND TAsks in MarZano's TAXonomy

\begin{tabular}{ccc}
\hline System & Level & Tasks \\
\hline Cognitive & Retrieval & Retrieval \\
& Comprehension & Analysis \\
& Utilization & $\begin{array}{c}\text { Matching, classifying, analyzing } \\
\text { errors, generalizing, specifying }\end{array}$ \\
& & $\begin{array}{c}\text { Decision making, problem solving, } \\
\text { experimenting, investigating }\end{array}$ \\
Metacognitive & Metacognitive & Specifying goals, process \\
& & monitoring, monitoring clarity and \\
& & accuracy \\
Self-system & Self-system & Examining importance, efficacy, \\
& & emotional response and overall \\
& & motivation \\
\hline
\end{tabular}

The function of the metacognitive system within the algorithm is not a continuation of the cognitive levels, so its role within the knowledge tracing system will be implemented as a function in which the student will be asked how many attempts they will need before the algorithm allows them to go to the next level, thus promoting goal setting and self-monitoring. The system will display the number of attempts that the learner estimated and will advise whether the prediction was correct or not. Fig. 3 shows the steps we propose for a student to pass a lesson, the steps carried out within each of the first three cognitive levels of Marzano's taxonomy (retrieval, comprehension, and analysis), and the step when the learner is asked to estimate the number of attempts it will take to pass.

Regarding the self-system, it is worth mentioning that the adaptive control will let the fastest learners to move forward easily and the slowest learners will be able to move according to their own pace, according to the adjustment of its parameters, avoiding the states of boredom and anxiety that appear when the level of challenge of the activities does not correspond to the student's abilities [34]. In the future, an Affective Tutoring System could be linked to be in charge of monitoring the aspects that correspond to the self-system. We would prefer a sensor-free system to avoid the system being invasive.

\section{Conclusion}

The main improvements of our proposal compared to computerassisted navigation based on cognitive levels are: 1) The adaptive transition between individual questions determined by levels of 


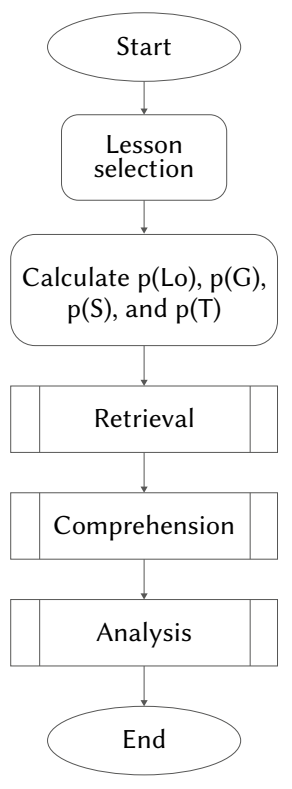

a)

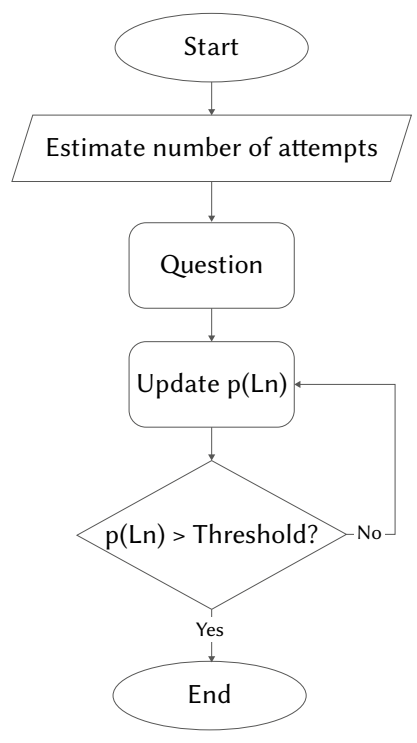

b)

Fig. 3. Proposed navigation through Marzano's taxonomy based on probabilistic parameters. a) Workflow of a lesson. b) Subprocess that represents the steps within retrieval, comprehension, and analysis.

cognition. 2) The possibility of starting the student model based on the general response of the group and adjusting it according to the ability of each learner. 3) The promotion of metacognitive skills such as goalsetting and self-monitoring.

It is worth mentioning that SAGE is based on individualized teaching that at the end of the lessons allows a comparison with the general performance of the group, so its point of comparison is not personalized and could have very different effects on students with different levels of performance. On the contrary, our proposal starts from common parameters that are adjusted in a personalized way, so that the point of comparison is the learners themselves and in this way the level of challenge can be according to their skill level.

In the field of Technology Enhanced Learning, it is important to bear in mind that there are mechanical and repetitive activities that are simple to perform but involve a large amount of time, and complex activities that require considerable effort to perform in a personalized way, especially in large groups. The first can be automated by means of simple resources, as in this case self-grading questionnaires are used for the first three cognitive levels. The second can be assisted by means of artificial intelligence tools, such as personalized transitions between levels according to the Bayesian model. However, there are many activities in which the human teacher has a great advantage over machines and automating them would lead to imprecise and incomplete processes, such as the evaluation of the knowledge utilization level of Marzano's taxonomy. As Sánchez-Prieto et al. [35] said, "it is the moment to reflect on the students' perceptions of being assessed by a non-conscious software entity like a machine learning model or any other artificial intelligence application".

Clearly delimiting the role of the intelligent tutor system and the human teacher based on a learning model, as in this case, will make it clear that the human teacher is not substitutable and that these types of systems are auxiliary tools for learning. That is, tools can be built to extend teachers' capabilities; for example, in Villagrá-Arnedo et al. [36], based on a probabilistic performance prediction system, teachers are given insights on students' learning trends to identify best moments for their intervention.

ACKNOWLEDGEMENT

Work partially funded by the PLeNTaS project, "Proyectos I+D+i 2019”, PID2019-111430RB-I00.

\section{REFERENCES}

[1] H. S. Nwana, "Intelligent tutoring systems: an overview," Artificial Intelligence Review, vol. 4, no. 4, pp. 251-277, 1990.

[2] Barr, A. and Feigenbaum, E, The Handbook of Artificial Intelligence. Volume 2. HeurisTech Press and William Kaufmann, Inc. Los Altos California, 1982.

[3] Hartley, J. R. and Sleeman, D. H. "Towards more intelligent teaching systems". International Journal of Man-Machine Studies, vol. 5, No.2, pp. 215-236, 1973.

[4] M. Badaracco and L. Martínez, "An intelligent tutoring system architecture for competency-based learning", in International Conference on Knowledge-Based and Intelligent Information and Engineering Systems, 2011, pp. 124-133.

[5] M. Beutelspacher, A. L. Franzoni, and A. Morales, "Sistema de apoyo generalizado para la enseñanza individualizada (SAGE)", Instituto Tecnológico Autónomo de México, México, 1995.

[6] Y. Long and V. Aleven, "Mastery-Oriented Shared Student/System Control Over Problem Selection in a Linear Equation Tutor", in Intelligent Tutoring Systems, vol. 9684, A. Micarelli, J. Stamper, y K. Panourgia, Eds. Cham: Springer International Publishing, 2016, pp. 90-100.

[7] G. Fenza, F. Orciuoli, and D. G. Sampson, "Building Adaptive Tutoring Model Using Artificial Neural Networks and Reinforcement Learning", in 2017 IEEE 17th International Conference on Advanced Learning Technologies (ICALT), 2017, pp. 460-462.

[8] G. Fenza and F. Orciuoli, "Building Pedagogical Models by Formal Concept Analysis", in Intelligent Tutoring Systems, vol. 9684, A. Micarelli, J. Stamper, y K. Panourgia, Eds. Cham: Springer International Publishing, 2016, pp. 144-153.

[9] V. Dimitrova and P. Brna, "From Interactive Open Learner Modelling to Intelligent Mentoring: STyLE-OLM and Beyond", International Journal of Artificial Intelligence in Education, vol. 26, no. 1, pp. 332-349, mar. 2016.

[10] R. Denaux, V. Dimitrova, L. Lau, P. Brna, D. Thakker, and C. Steiner, "Employing linked data and dialogue for modelling cultural awareness of a user", in Proceedings of the 19th international conference on Intelligent User Interfaces - IUI '14, Haifa, Israel, 2014, pp. 241-246.

[11] A. K. Goel and L. Polepeddi, "Jill Watson: A Virtual Teaching Assistant for Online Education", p. 21.

[12] M. Magdin, D. Držík, J. Reichel, and S. Koprda, "The Possibilities of Classification of Emotional States Based on User Behavioral Characteristics". International Journal of Interactive Multimedia and Artificial Intelligence, vol. 6, no. 4, pp. 97-104. 2020. http://doi. org/10.9781/ijimai.2020.11.010

[13] P. Pham and J. Wang, "Adaptive review for mobile MOOC learning via implicit physiological signal sensing", in Proceedings of the 18th ACM International Conference on Multimodal Interaction - ICMI 2016, Tokyo, Japan, 2016, pp. 37-44.

[14] J. Hernandez, P. Paredes, A. Roseway, and M. Czerwinski, "Under pressure: sensing stress of computer users", in Proceedings of the 32nd annual ACM conference on Human factors in computing systems - CHI '14, Toronto, Ontario, Canada, 2014, pp. 51-60.

[15] A. K. Vail, J. F. Grafsgaard, K. E. Boyer, E. N. Wiebe, and J. C. Lester, "Predicting Learning from Student Affective Response to Tutor Questions", in Intelligent Tutoring Systems, vol. 9684, A. Micarelli, J. Stamper, y K. Panourgia, Eds. Cham: Springer International Publishing, 2016, pp. 154-164.

[16] M. Taub and R. Azevedo, "Using Eye-Tracking to Determine the Impact of Prior Knowledge on Self-Regulated Learning with an Adaptive Hypermedia-Learning Environment", in Intelligent Tutoring Systems, vol. 9684, A. Micarelli, J. Stamper, y K. Panourgia, Eds. Cham: Springer International Publishing, 2016, pp. 34-47.

[17] R. Janning, C. Schatten, and L. Schmidt-Thieme, "Perceived task-difficulty recognition from log-file information for the use in adaptive intelligent tutoring systems", International Journal of Artificial Intelligence in Education, vol. 26, no. 3, pp. 855-876, 2016. 
[18] M. Wixon, I. Arroyo, K. Muldner, W. Burleson, D. Rai, y B. Woolf, "The opportunities and limitations of scaling up sensor-free affect detection", in Educational Data Mining 2014, 2014.

[19] M. A. Azim and M. H. Bhuiyan, "Text to Emotion Extraction Using Supervised Machine Learning Techniques", Telkomnika, vol. 16, no. 3, 2018.

[20] D. C. Muñoz, A. Ortiz, C. Gonzalez, D. M. Lopez, and B. Blobel. "Effective e-learning for health professional and medical students: The experience with SIAS-intelligent tutoring system". Studies in Health Technology and Informatics, Vol. 156, pp. 89-102. 2010.

[21] R. Costello. "Adaptive intelligent personalised learning (AIPL) environment (U621351 Ph.D.)", University of Hull (United Kingdom), Ann Arbor. ProQuest Dissertations and Theses A\&I; ProQuest Dissertations \& Theses Global database. 2012.

[22] L. S. Myneni, N. H. Narayanan, S. Rebello, A. Rouinfar, and S. Pumtambekar. "An interactive and intelligent learning system for physics education”. IEEE Transactions on Learning Technologies, Vol. 6, no. 3, pp. 228-239. doi:10.1109/TLT.2013.26

[23] D. Weragama and J. Reye. "Analysing student programs in the PHP intelligent tutoring system". International Journal of Artificial Intelligence in Education, vol. 24, no. 2, pp. 162-188. 2014.

[24] D. Hooshyar, R. B. Ahmad, M. Yousefi, F. D. Yusop, and S.J. Horng. "A flowchart-based intelligent tutoring system for improving problemsolving skills of novice programmers". Journal of Computer Assisted Learning, vol. 31(4), pp. 345-361. 2015.

[25] B. Grawemeyer, M. Mavrikis, W. Holmes, G. S. Sergio, M. Wiedmann and N. Rummel. "Affecting Off-task Behaviour: How affect-aware feedback can improve student learning". ACM international Conference Proceeding Series. 2016.

[26] N. El Ghouch, E.-N. El Mokhtar and Y. Z. Seghroucheni. "Analysing the outcome of a learning process conducted within the system ALS_CORR [LP]”. International Journal of Emerging Technologies in Learning, vol. 12, no. 3, pp. 43-56. 2017.

[27] F. Grivokostopoulou, I. Perikos and I. Hatzilygeroudis. "An educational system for learning search algorithms and Automatically Assessing student performance". International Journal of Artificial Intelligence in Education, vol. 27, no. 1, pp. 207- 240. doi:10.1007/s40593-016-0116-x. 2017.

[28] B. Mostafavi, and T. Barnes. "Evolution of an intelligent deductive logic tutor using data-driven elements". International Journal of Artificial Intelligence in Education, vol. 27, no. 1, pp. 5-36. 2017.

[29] B. S. Bloom, "Taxonomy of educational objectives. Vol. 1: Cognitive domain", N. Y. McKay, pp. 20-24, 1956

[30] A. T. Corbett and J. R. Anderson, "Knowledge tracing: Modeling the acquisition of procedural knowledge", User Modeling and User-Adapted Interaction, vol. 4, no. 4, pp. 253-278, 1995.

[31] R. C. Atkinson and J. A. Paulson, "An approach to the psychology of instruction”, Psychol. Bull., vol. 78, no. 1, pp. 49-61, 1972.

[32] R. S. J. d. Baker, A. T. Corbett, and V. Aleven, "More Accurate Student Modeling through Contextual Estimation of Slip and Guess Probabilities in Bayesian Knowledge Tracing", in Intelligent Tutoring Systems, vol. 5091, B. P. Woolf, E. Aïmeur, R. Nkambou, y S. Lajoie, Eds. Berlin, Heidelberg: Springer Berlin Heidelberg, 2008, pp. 406-415.

[33] R. J. Marzano and J. S. Kendall, The new taxonomy of educational objectives. Corwin Press, 2006.

[34] M. Csikszentmihalyi, Applications of Flow in Human Development and Education. Dordrecht: Springer Netherlands, 2014.

[35] J.C. Sánchez-Prieto, J Cruz-Benito, R. Therón, and F. García-Peñalvo, "Assessed by Machines: Development of a TAM-Based Tool to Measure AI-based Assessment Acceptance Among Students". International Journal of Interactive Multimedia and Artificial Intelligence, vol. 6, no. 4, pp. 80-86, 2020. http://doi.org/10.9781/ijimai.2020.11.009

[36] C.J. Villagrá-Arnedo, F.J. Gallego-Durán, F. Llorens-Largo, R. SatorreCuerda, P. Compañ-Rosique, and R. Molina-Carmona, "Time-Dependent Performance Prediction System for Early Insight in Learning Trends". International Journal of Interactive Multimedia and Artificial Intelligence, vol. 6, no. 2, pp. 112-124, 2020. http://doi.org/10.9781/ijimai.2020.05.006

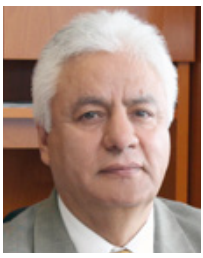

Francisco Cervantes-Pérez

Francisco Cervantes-Perez. He received his B.E. in Mechanical Electrical Engineering and a M.E. in Electrical Engineering, both from the National Autonomous University of Mexico (UNAM), and his Ph.D. in Computer and Information Sciences from the University of Massachusetts at Amherst, Mass, USA. He is a member of the National System of Researchers in Mexico, the Mexican Academy for Informatics, the Mexican Academy for Computer Science, the Mexican Society for Artificial Intelligence, among other. His main research interests are in Computational Neuroscience, Artificial Intelligence, Ecological Robotics, and Technologies for On-line Education. Currently, he is the Rector of the International University of La Rioja in Mexico.

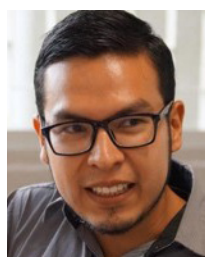

Joaquin Navarro-Perales

Joaquin Navarro-Perales is an academic technician in Coordinación de Universidad Abierta, Innovación Educativa y Educación a Distancia (CUAIEED), at Universidad Nacional Autónoma de México (UNAM). He has a master's degree in Centro de Investigación y de Estudios Avanzados del Instituto Politécnico Nacional (CINVESTAV) and received his bachelor's degree in Biomedical Engineering from Universidad de Guadalajara (UDG). Currently, he is a $\mathrm{PhD}$ student in Computer Science at Universidad Internacional de la Rioja (UNIR), and he is working towards a bachelor's degree in Pedagogy at Universidad Nacional Autónoma de México (UNAM). His research interests include Intelligent Tutoring Systems, Self-Regulated Learning, and Pedagogical Conversational Agents.

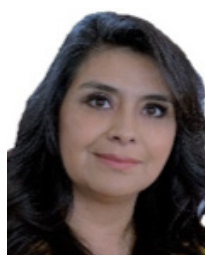

Ana L. Franzoni-Velázquez

Dr. Franzoni is a full-time professor and director of the Computer Engineering degree program at the Instituto Tecnológico Autónomo de México (ITAM). She has a $\mathrm{PhD}$ in Knowledge Engineering and Information Systems from the Université de Technologie de Troyes (UTT) and TELECOM \& Management SudParis (France). Her Master's degree is in Information Technology and Management from ITAM and she also has a master's degree in Networks and Information Systems for Companies from the École Nationale Supérieure des Télécommunications de Bretagne (ENSTB) (France). Her undergraduate degree is in Computer Engineering, at ITAM. Dr. Franzoni specializes in Technology in Education, learning environments, computer skills, intelligent tutorial systems and learning analytics. She has produced several academic publications with international arbitration that have appeared in journals, book chapters and conferences. She also is an editorial board member in different journals. Dr. Franzoni has been a visiting professor at San Jose State University (California) and at TELECOM \& Management SudParis (France). Dr. Franzoni is the director of the laboratories for mobile devices, Web and videogames at ITAM and in this context she develops links with companies involved in mobile application design, video games and emerging technologies. Dr. Franzoni is a member of the National Association of Educational Institutions in Information Technology, A.C. (ANIEI), evaluator of the National Council of Accreditation in Computer Science A.C. (CONAIC), member of the Mexican Society of Computing in Education, A.C.(SOMECE), member 259 of the Mexican Academy of Information Technology, A.C.(AMIAC), member of the Mexican Association of the Information Technology Industry (AMITI).

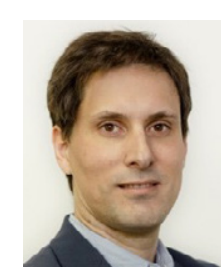

\section{Luis de la Fuente Valentín}

Dr. Luis de-la-Fuente-Valentín is a full-time associate professor at Universidad Internacional de La Rioja (UNIR), at the School of Engineering and Technology. Before joining this institution, he obtained his degree in Telecommunication Engineering in 2005 and then he started a research grant at Universidad Carlos III de Madrid, where he obtained his PhD in 2011. He leads the Data Science research group, with research topics focused on artificial intelligence, machine learning techniques, natural language processing and data centered applications. He has authored more than 40 papers and participated in several Spanish and European public funded projects, one of them as investigator in charge. His research experience focuses on Technology Enhanced Learning, Learning Analytics and Natural Language Processing applied to the educational field. 